\title{
Grounding, explanation, and multiple realization in mathematics and ethics
}

Document Version

Accepted author manuscript

Link to publication record in Manchester Research Explorer

\section{Citation for published version (APA):}

Liggins, D. (2016). Grounding, explanation, and multiple realization in mathematics and ethics. In N. Sinclair, \& U. Liebowitz (Eds.), Explanation in Ethics and Mathematics: Debunking and Dispensability (pp. 168-194). Oxford University Press.

\section{Published in:}

Explanation in Ethics and Mathematics

\section{Citing this paper}

Please note that where the full-text provided on Manchester Research Explorer is the Author Accepted Manuscript or Proof version this may differ from the final Published version. If citing, it is advised that you check and use the publisher's definitive version.

\section{General rights}

Copyright and moral rights for the publications made accessible in the Research Explorer are retained by the authors and/or other copyright owners and it is a condition of accessing publications that users recognise and abide by the legal requirements associated with these rights.

\section{Takedown policy}

If you believe that this document breaches copyright please refer to the University of Manchester's Takedown Procedures [http://man.ac.uk/04Y6Bo] or contact uml.scholarlycommunications@manchester.ac.uk providing relevant details, so we can investigate your claim.

\section{OPEN ACCESS}




\section{Grounding, explanation, and multiple realization in mathematics and ethics}

\section{David Liggins}

Please do not cite this version. The published version is: David Liggins, 'Grounding, explanation, and multiple realization in mathematics and ethics' in Neil Sinclair and Uri Liebowitz (eds) Explanation in Ethics and Mathematics: Debunking and Dispensability. Oxford: Oxford University Press, 2016, 168-184.

\section{Inference to the best explanation arguments for realism}

Consider the following arguments for moral realism:

The revolt occurred because the society was unjust.

If the revolt occurred because the society was unjust, then moral realism is true.

Therefore moral realism is true.

The onlooker believes that the cat's treatment is wrong because the cat's treatment is wrong.

If the onlooker believes that the cat's treatment is wrong because the cat's treatment is wrong, then moral realism is true.

Therefore moral realism is true.

Now consider the following arguments for mathematical realism:

The tiles cannot be arranged into a rectangle because the number of tiles is prime.

If the tiles cannot be arranged into a rectangle because the number of tiles is prime, then mathematical realism is true.

Therefore mathematical realism is true.

You could not walk through Königsberg crossing each bridge exactly once because Königsberg's graph was non-Eulerian (i.e. has a vertex of odd degree).

If you could not walk through Königsberg crossing each bridge exactly once because Königsberg's graph was non-Eulerian, then mathematical realism is true. 
Therefore mathematical realism is true. ${ }^{1}$

Arguments along these lines have generated rich debates in metaethics and the philosophy of mathematics. Viewed at the right level of generality, all these arguments have the same structure. The first premiss is that the best explanation of some phenomenon is moral or mathematical; the second is that the explanation implies the relevant form of realism. My aim in this paper is to bring together these two debates and thereby advance them both. ${ }^{2}$

I will be concerned only with the first premiss of each of these arguments. Consequently, there is no need to spend time defining 'mathematical realism' or 'moral realism'. For my purposes, all I need say is that mathematical realists believe in the existence of mathematical entities such as numbers and graphs, and moral realists believe in the existence of genuine moral properties such as wrongness and injustice.

To begin with, I will set out a challenge to the first premiss of the metaethical arguments, and explain the 'multiple realization' objection which it provokes (section 2). I then turn to philosophy of mathematics, and show that the same moves can take place here: the first premiss of inference to the best explanation arguments for mathematical realism invite a corresponding challenge, and there is a corresponding 'multiple realization' objection to the response (section 3). I propose a way of improving the challenges to the arguments in both cases, so that they no longer provoke the 'multiple realization' objection (section 4). Finally, I discuss some objections and relate my argument to some recent work by Brad Majors (section 5). My intention is to undermine the first premises of the inference to the best explanation arguments, and thereby to weaken the cases for moral and mathematical realism.

Although I concentrate on the first premiss of each of the arguments, that does not mean that I think the second premises are trivial. In fact, they are far from trivial. In the mathematical case, the second premiss is challenged by attempts to paraphrase away apparent reference to mathematical entities. Paraphrasers hold that claims apparently about explanatory mathematical entities such as numbers and graphs do not require the existence of these entities for their truth (e.g. Chihara 1990) In the moral case, the second premiss is challenged by expressivist accounts of moral explanations. According to this approach, it is a mistake to infer moral realism from claims such as 'The revolt

1 The examples are based on Brink 1989: 195, Harman 1977: 4-5, Yablo 2012: 1021, and Pincock 2007: 257-9. See also Lyon 2012.

${ }^{2}$ For introductions to the moral and mathematical debates, see Majors 2007 and Colyvan 2001 respectively. 
occurred because the society was unjust' (Sinclair 2011). A full assessment of inference to the best explanation argument for moral and mathematical realism must take these and other challenges to the second premises into account.

\section{Metaethics and multiple realization}

In order to set out a particular challenge to the inference to the best explanation arguments for moral realism, it is necessary to set out the notion of grounding. Though arguably implicit in a great deal of philosophical writing, and expressed by some phrases of ordinary English ('in virtue of', for instance), it is only recently that grounding has become the subject of sustained metaphysical investigation. Some philosophers deny that there is any distinctive concept worth discussing. Whilst I won't discuss these sceptical arguments here, I will try to introduce the notion of grounding in a way which makes the sceptic's task difficult.

Consider the following examples:

Socrates' singleton set exists because Socrates does (see Fine 1995: 271-2).

This food is hot in virtue of the chilli it contains.

Alex acts with politeness by sending thank-you letters (cf. Schnieder 2009).

It's false that everything is a table, because there are counterexamples.

These all seem to be cases of dependence. The existence of Socrates' singleton depends on the existence of Socrates; the taste of the food depends on its ingredients; whether Alex acts with politeness depends on what precisely Alex does; and the falsity of the generalization depends on the existence of counterexamples. These cases of dependence seem not to be governed by any causal laws, so it is plausible that they are not cases of causal dependence. We can introduce grounding as a term for the phenomenon of non-causal dependence. Note that, in order to introduce grounding, the examples only have to be understood. For instance, someone who maintains that there are no sets and so denies the first example can still use it to gain insight into what is meant by 'grounding'.

Grounding is closely related to non-causal explanation. The first example is an explanation, and the others immediately give rise to them:

Why is this food hot? Because it contains chilli.

Why does Alex act with politeness? Because he sends thank-you letters. 
Why isn't it true that everything is a table? Because there are counterexamples.

It would be strange to class these explanations as causal. Although the term 'grounding' is relatively unfamiliar, non-causal explanations are frequently encountered in philosophy.

Grounding is to be distinguished from supervenience. The latter is a modal notion - the claim that certain variations are impossible - whereas grounding cannot be understood in purely modal terms. As Fine (1995: 271-2) argues, the existence of Socrates' singleton supervenes on the existence of Socrates, and vice versa, whereas the dependence runs in one direction only: from the existence of Socrates to the existence of his singleton. Similarly, what is true supervenes on what there is and how it is, and vice versa, even though the dependence only runs in one direction: from what there is and how it is to what is true (Rodriguez-Pereyra 2005: 19, 21). The fact that necessities supervene on everything but do not depend on everything provides another reason to distinguish grounding from supervenience. Although grounding is distinct from supervenience, metaphysicians regard the two as intimately related: where there is supervenience, grounding often underlies and thereby explains it.

The metaphysics of grounding is currently unresolved. For convenience, I will assume the convenient theory that grounding is a relation between facts, so that (for instance) the fact that Socrates exists grounds the fact that Socrates' singleton exists (see Rosen 2010). But I think that my argument does not require this assumption. As well as using the predicate 'grounds', I will also use 'in virtue of' and 'because' to articulate claims of grounding. Aficionados will know how to distinguish full from partial grounding (Rosen 2010: 115); by 'grounding' I mean the latter. ${ }^{3}$

Now that the notion of grounding has been introduced, let me set it to work in providing a response to the inference to the best explanation arguments for moral realism.

Moral realists readily agree that the moral supervenes on the non-moral: how things are in nonmoral respects necessitates how they are in moral respects. Indeed, it is plausible that if moral realism is true, then the moral depends on the non-moral: things have the moral properties they do in virtue of having the non-moral properties they do. Thus, for instance, it is never a brute fact that a society is unjust: an unjust society is always unjust in virtue of having some non-moral property or

\footnotetext{
${ }^{3}$ An alternative way of introducing the notion of grounding would be via its formal properties - but since these are hotly disputed, this way of introducing grounding risks changing the subject. Moreover, it invites the sceptic about grounding to deny that giving formal properties is enough to endow 'grounds' with content (see Daly 2012). For introductions to grounding, see Correia and Schnieder 2012, Clark and Liggins 2012, and Trogdon 2013.
} 
other. For instance, perhaps it is unjust in virtue of having a discriminatory legal system (where that notion is understood in a suitably non-moral fashion). This dependence is not plausibly regarded as causal, so we have a case of grounding. For moral realists, the moral is grounded in the non-moral (cf. Zangwill 2006: 270-1 on the 'Because Constraint').

This suggests a way of defeating the first premises of the inference to the best explanation arguments. In the first argument given in section 1, the moral realist claims that the injustice of the society explains the occurrences of the revolt. Since they hold that the moral is grounded in the nonmoral, they must hold that the society was unjust because it had some non-moral property; suppose that property is possession of a discriminatory legal system. Then the opponent of the argument may argue that the revolt occurred not because the society was unjust, but because it had a discriminatory legal system - thereby challenging the first premiss. Where the moral realist appeals to an alleged moral fact, their opponent appeals to its alleged non-moral ground. And so more generally: where the realist explains some phenomenon by ascribing a moral property, they must think that the entity in question has the property in virtue of having some non-moral property. This offers the opponent of the argument a way of constructing a rival explanation: explain the phenomenon by appeal to the non-moral fact that the entity in question has the non-moral property. The challenge is to show that the moral explanation is superior.

In the ensuing debate, the opponent of realism can exploit some dialectical advantages. The moral realist cannot dispute the existence of the non-moral fact to which their opponent appeals, on pain of inconsistency. So their only option is to maintain that the non-moral explanation is inferior. But because the realist claims to have the best explanation of the phenomenon, all their opponent needs to show is that it is not clear that the realist's explanation is better. They need not show that their explanation is superior to the realist's.

This challenge to the inference to the best explanation argument for realism faces an objection the 'multiple realization' objection - which I will now set out.

Moral properties, if there are any, are multiply realizable. To take the case of injustice: there are many different non-moral properties in virtue of which something could be unjust. Perhaps one society is unjust in virtue of having a discriminatory legal system, whereas another (actual or possible) society is unjust in virtue of having an unequal income distribution. The possession of the same moral property may be grounded by the possession of different non-moral properties in different cases. Several philosophers have argued that this implies that the non-moral explanation is inferior to the original. The original is illuminating in a way that the replacement is not. Appeal to 
moral facts provides explanatory insight that their grounds do not provide (see e.g. Railton 1998: 179-180). As Sayre-McCord (1988: 449) puts the point:

Moral explanations allow us to isolate what it is about a person, or an action, or an institution, that leads to its having the effects it does. And these explanations rely on moral concepts that identify characteristics common to people, actions, and institutions that are uncapturable with finer-grained or differently structured categories.

The non-moral explanation 'supplements, rather than supplants' the moral explanation (Brink 1989: 193).

Other cases of realization provide parallels. For instance, it is plausible that the psychological is grounded in the neuro-physiological, but implausible that neuro-physiological explanations of human action are superior to psychological ones. In the same way, the strategy of appealing to the grounds of the alleged moral fact faces the 'multiple realization' objection.

\section{Mathematics and multiple realization}

The inference to the best explanation argument for mathematical realism is also known as the 'indispensability argument'. A leading opponent of the argument states it as follows:

[I]f our belief in electrons and neutrinos is justified by something like inference to the best explanation, isn't our belief in numbers and functions and other mathematical entities equally justified by the same methodology? After all, the theories that we use in explaining various facts about the physical world not only involve a commitment to electrons and neutrinos, they involve a commitment to numbers and functions and the like. (Field 1989: 16)

One way to reply to the indispensability argument is to mimic the response discussed in the previous section. Suppose the realist claims that the reason the tiles cannot be arranged into a rectangle is that the number of tiles is prime. The opponent of the argument can point out that realists should believe mathematical facts about numbers of tiles to be grounded by facts about tiles. In a particular case, for instance, mathematical realists should believe that number of tiles is prime in virtue of the fact that there is a tile, another tile, and no more tiles. The opponent of the argument 
may seek to exploit this by arguing that the reason the tiles cannot be arranged into a rectangle is not that the number of tiles is prime but that there is a tile, another tile, and no more tiles.

Why was it impossible to walk through Königsberg crossing each bridge exactly once? In response to the realist who argues invokes Königsberg's graph to explain this phenomenon, a similar response is available. Mathematical realists believe that which graph is Königsberg's depends on the physical structure of the city (I suppose this is the property of containing certain locations connected by such-and-such paths). Building more bridges, or destroying them, changes the city's graph-theoretical structure. So perhaps the explanation of why you cannot walk through Königsberg crossing each bridge exactly once is that the city has a particular physical structure, not that its graph is non-Eulerian.

More generally, it is arguable that mathematical realists should think that the alleged facts about mathematical entities which the realists invoke in their explanations are grounded by facts about physical objects - facts which opponents of mathematical realism are free to posit. This provides a way of responding to the inference to the best explanation argument: as in the examples, appeal to some physical fact which the mathematical realist should claim grounds their alleged mathematical fact.

Indispensability arguments in the philosophy of mathematics have the following structure. The first premiss is that the best explanation of some phenomenon is mathematical; the second is that the explanation implies mathematical realism. Mark Colyvan (2010) has distinguished two sorts of response to these arguments. The hard road is to refuse to accept the first premises of the arguments; the easy road is to refuse to accept the second premises. Those who take the hard road reply offer alternative explanations of the phenomena, and argue, first, that these alternative explanations do not imply mathematical realism, and, second, that they are as good as or better than those explanations the proponents of the indispensability argument claim to be the best. By contrast, those who take the easy road maintain that, even if the best explanations of some phenomenon or phenomena are mathematical, mathematical realism does not follow. The most famous hard road response is Hartry Field's (Field 1980, 1989), which was the subject of intense discussion during the 1980s and 90s; more recent debate has tended to focus on the easy road. The strategy under discussion here is an example of a hard road response. ${ }^{4}$

\footnotetext{
${ }^{4}$ See REFERENCE REMOVED and Plebani MS for more detailed discussion of this strategy.
} 
The response faces the same 'multiple realization' objection as before. The number of tiles being prime is multiply realizable in that sometimes the number of tiles is prime because there is a tile, another tile, and no more tiles, but sometimes it is because there is a tile, another tile, another tile, and no more tiles; sometimes because there is a tile, another tile, another tile, another tile, another tile, and no more tiles; and so on. The explanation which uses the concept prime number unites these different scenarios and thereby provides explanatory insight which is lost if we focus on the more detailed facts to do with tiles rather than numbers. The same goes for the graph theory example. There are many different physical structures which give rise to a non-Eulerian graph (if any do): in this sense, having a non-Eulerian graph is multiply realizable. Explanatory insight is lost if we point to the physical structure of the city and ignore what it has in common with other cities whose structures give rise to a non-Eulerian graph. Just as before, it seems that the opponent's explanation 'supplements, rather than supplants' the realist's explanation, because the latter groups things together in an explanatorily indispensable way. ${ }^{5}$

What is the extent of the problem? It is arguable that fundamental physical quantities are immune from it. Suppose mass is a fundamental physical quantity. In virtue of what would something be related to the number 4 by the mass-in-kg relation? Perhaps there is only a single physical property which could act as ground ('having-mass-4-kg'). But derivative physical quantities are multiply realizable. For instance, suppose something's density is grounded in its mass and volume. Bearing the density-in- $\mathrm{kg}_{\mathrm{g}} \mathrm{m}^{-3}$ relation to 4 could be grounded in several different things: having-mass-4-kg and having-volume-1- $\mathrm{m}^{3}$; having-mass-8-kg and having-volume-2- $\mathrm{m}^{3}$; and so on. The problem is serious: to establish their conclusion, the realist only needs a single sound inference to the best explanation argument. As in the ethical case, then, the strategy of appealing to the grounds of the alleged mathematical fact faces the 'multiple realization' objection.

\section{How to avoid the multiple realization objection}

My aim in this section is to improve the challenge to the inference to the best explanation arguments so that it escapes the 'multiple realization' objection. In a nutshell, the idea is to appeal to less fundamental grounds of the realists' alleged facts.

The challenge is to defeat the first premiss of each argument for realism by providing a nonmathematical or non-moral explanation of the phenomenon in question which is not clearly inferior

\footnotetext{
${ }^{5}$ Plebani MS, section 3 raises this objection in response to REFERENCE REMOVED.
} 
to the realist's proposed explanation. The problem is that the explanations proposed so far fail to do this. Just why they fail is a difficult question, but a partial answer is that they appeal to facts which are excessively specific. When explaining why the revolt occurred, it seems wrong to mention that the society had a discriminatory legal system without mentioning that the society was unjust. The legal system is relevant only because it gave rise to injustice. In the same way, to explain why we cannot arrange the tiles into a rectangle by pointing out that there is a tile, another tile, and no more tiles, is to load the candidate explanation with detail that on its own is irrelevant. It is worth noting here that there are salient generalizations at the higher level in both cases: that unjust societies tend to provoke revolts, and that the tiles cannot be arranged into a rectangle if the number of them is prime. The explanations offered so far provide too much information. If brought in to deepen a moral or mathematical explanation, this information is of explanatory relevance: 'The revolt took place because the society was unjust, and the injustice of the society consisted in its possessing a discriminatory legal system'. But when offered as the whole of the explanation, an important level of generality is missed out. The basic explanation takes place at a higher level.

To make the strategy work, opponents of the first premises must therefore offer explanations of the phenomena which, in addition to being non-moral or non-mathematical, are not too specific to forfeit explanatory insight. My suggestion is that realists should think their alleged moral or mathematical facts have grounds which are less specific than those already mentioned; and that the strategy can be improved by appeal to these less specific facts.

In the hierarchy of grounding, what fact could lie between the fact that the society was unjust and the fact that the society had a discriminatory legal system? We require a fact which would obtain in every case where the realist maintains that a society is unjust. We could pick out a suitable fact like this: 'The fact that the society was such that, if moral realism were true, it would be unjust.' Or like this: 'The fact that the society had an alleged realizer of injustice' - 'alleged' because the opponent of the argument for realism must be able to posit this fact without endorsing realism. Realists will simply refer to the same fact as 'The fact that the society had a realizer of injustice'.

In the mathematical case, the strategy requires a fact that is intermediate in the grounding hierarchy between the fact that the number of tiles is prime and the fact that there is a tile, another tile, and no more tiles. We could pick it out like this: 'The fact that the tiles are such that, if mathematical realism were true, the number of the tiles would be prime' (cf. Dorr 2008: 37). Or we could pick it out like this: 'The fact that the tiles are primely many'. This fact must be distinguished from the fact that the number of tiles is prime: it has to be understood as a fact which could obtain 
even if there are no numbers. It may be thought of as an infinitely disjunctive fact, of which the fact that there is a tile, another tile, and no more tiles is the first disjunct and the one which is quickest to state.

If the relevant moral and mathematical facts obtain, it is very plausible that the facts just introduced are among their grounds. If the society was unjust, it was in virtue of having an alleged realizer of injustice. The fact that the society had a discriminatory legal system is still a ground of the fact that the society is unjust, grounds the fact that the society had an alleged realizer of injustice. The fact that the society had a discriminatory legal system is thereby still a ground of the fact that the society is unjust, but a less fundamental one. ${ }^{6}$ The three facts form the following chain of grounding:

The fact that the society was unjust

is grounded by

The fact that the society had a realizer of injustice

is grounded by

The fact that the society had a discriminatory legal system

Mathematical realists maintain that it is a fact that the number of tiles is prime. If they are right, then we have the same structure in the mathematical case:

The fact that the number of tiles is prime

is grounded by

The fact that the tiles are primely many

is grounded by

The fact that there is a tile, another tile, and no more tiles

The first link is evident. The second link follows from the fact that there being a tile, another tile, and no more tiles is a way for the tiles to be primely many.

\footnotetext{
${ }^{6}$ Here I presuppose that in the cases under discussion here, grounding is transitive: if $x$ is grounded by $y$ and $y$ by $z$, then $x$ is grounded by $z$ (Rosen 2010: 116). Schaffer 2012 and Raven 2013 debate this principle.
} 
In different circumstances, the first two facts in each chain may both hold while a different fact may replace the third one: that is multiple realizability. But it is hard to see how a different fact could replace the second one whilst the first remains the same. In whatever way the society was unjust, it would be unjust in virtue of having some realizer of injustice. That is because the moral is always grounded in the non-moral. If the number of tiles is prime, that is always because the tiles are primely many. The second fact in each chain is not one of many possible realizers. In other words, the second fact lacks the specificity of the third, being at a higher level of generality. To defeat the inference to the best explanation arguments for realism, we were looking for non-moral or non-mathematical facts which are not too specific to forfeit explanatory insight. It seems we have found them.

Let me flesh out this point. Suppose that a moral realist argues for realism partly by claiming that the injustice of the society explains the occurrence of the revolt. Proponents of the strategy I am putting forward place a new candidate explanation on the table: they claim that the revolt occurred not because the society was unjust, but because the society had an alleged realizer of injustice; and they challenge the realist to establish that this explanation is inferior. It is at this point in the debate that the realist might try to attack the new explanation by appeal to multiple realizability. That is to say, they might claim that the new explanation is less illuminating because it is at the wrong level of specificity: unlike the realist's favoured explanation, the new explanation is weighed down with irrelevant detail. But this attack on the new explanation is a failure: multiple realizability is no longer of any use to the realist. That is because the facts to which the opponent of realism now appeals are at the right level of specificity, and it is false that they contain irrelevant detail. The first version of the strategy was open to the multiple realization objection but the latest version is immune from it. Appealing to less fundamental grounds of the realists' alleged facts enables opponents of the inference to the best explanation arguments to escape the multiple realization objection.

\section{Objections and replies}

One natural objection is that the proposal proves too much. It would prevent us from ever establishing the existence of higher-level facts via inference to the best explanation, because we could always explain the phenomenon by appeal to a suitably general lower-level fact instead. Majors $(2003,2007)$ raises this in response to the first version of the challenge (echoing Sturgeon 1985), but it also applies to the improved version I have just offered. 
The main flaw in this objection is that the proposal offers a challenge to the inference to the best explanation arguments, not a knock-down objection to them. The strategy is to offer an alternative explanation and then challenge the realist to show that their favoured explanation is preferable. It is a recipe for creating candidate explanations, not an argument that they all succeed. Whether in any particular case the realist is able to establish the adequacy of their favoured explanation is a further question; I have not argued that the realist is never able to do so. Each candidate explanation must be assessed on its merits, and there is no reason to think that if the strategy defeats one inference to the best explanation argument for realism, it will defeat them all. It is worth mentioning that to defeat an argument for the existence of higher-level facts is not to establish that the facts do not exist. So even if the challenge were to dispatch all the inference to the best explanations for higherlevel facts, that would not show that these facts do not exist. Perhaps the reasons to believe in some of these facts have nothing to do with inference to the best explanation, but are a priori in character.

Another sort of objection is that the new explanations are unintelligible. One of these explanations appeals to the fact that the society was such that, if moral realism were true, it would be unjust. It might be argued that moral realism is a non-contingent matter, so those who deny moral realism cannot make sense of what would be the case if it were true.

This argument relies on the idea that we cannot make sense of counterfactuals with impossible antecedents. I find this idea implausible. For instance, it seems clear that if I had proved the negation of Fermat's Last Theorem, I would have made a major mathematical achievement. But the matter is a controversial one (contrast, for instance, Nolan 1997: section 2 with Williamson 2007: 171-5) and so stalemate threatens.

A more promising response to the objection is to point out that it is dialectically confused. The realist is offering an inference to the best explanation argument for realism; their opponent offers a rival explanation, claims it is no worse than the realist's, and challenges the realist to show otherwise. It does not matter if the rival explanation is unintelligible to the opponent of realism: since realists think realism is true, they should be able to make sense of the idea of a society's being such that, if moral realism were true, it would be unjust; and so they should be able to make sense of the rival explanation. Since realists believe that the moral is grounded in the non-moral, they can understand the idea that some non-moral characteristics of societies make them unjust and others do not. The fact in question is the fact that the society has one of the former characteristics - which is why it can also be called 'the fact that the society had an alleged realizer of injustice'. Even if, by the realist's lights, their opponents should find the rival explanation unintelligible, realists have no 
reason to claim that the rival explanation is unintelligible. So appeal to unintelligibility does not allow the realist to duck the task of establishing that the rival explanation is inferior to their own. ${ }^{7}$ Corresponding points obtain in the mathematical case. Anyone who believes that the number of tiles is prime believes there are some circumstances in which the tiles are such that their number is prime. Since mathematical realism is controversial, it is controversial whether these circumstances do indeed give rise to the number of tiles being prime - but it is clear which fact their opponent cites: the fact that these circumstances obtain. The task of the realist is to establish that this fact yields an inferior explanation.

To finish, let me comment on the following discussion of the significance of multiple realizability:

Moral properties, like mental properties, cannot be reduced to lower-level types because there are no necessary physical conditions upon the satisfaction of moral, or mental predicates. The property of being morally good is multiply realizable physically, which means that there can be no necessary and sufficient conditions, specifiable in non-moral vocabulary, for possession of the property. But if this is the case, then no non-moral predicate can pick out the moral property in question. And if no nonmoral predicate can pick out the property of being morally good, then any explanatory work done by adverting to the property can be done only at the level of moral theory. To put the point slightly more concretely, suppose the fall of a government is explained by citing the injustice of its rule. Here we advert, if only implicitly, to the causal law 'injustice causes revolt' .... Now the explanatory work done by citing this causal law could be done by another discipline only if the property of being unjust could be picked out by a non-moral predicate. But that is precisely what the multiple realizability of moral properties precludes. (Majors 2007: 139-40, footnotes omitted) ${ }^{8}$

\footnotetext{
${ }^{7}$ A rough analogy may help here. Suppose we are disputing whether there is a bump on the back of my head: I claim that there is, whereas you deny its existence. To make progress with this debate, it is perfectly proper for me to show you the back of my head so that you can see the bump for yourself. Since I cannot see the back of my own head, I cannot see the bump, but if you can see it then you are in a position to see that I am right. To point out that I cannot see the evidence which I cite would leave my argument undefeated.

${ }^{8}$ Cuneo (2006: 154) contains similar sentiments:

Even if we grant that moral facts are determined by natural ones, both the "shapelessness" and "thickness" of moral facts of certain types guarantees that we cannot construct the requisite type of configuring cause explanations only in terms of the determining natural features. ... [W]e are not able to
} 
Majors claims that if we confine ourselves to non-moral language, multiple realizability prevents us from giving necessary and sufficient conditions for being morally good. This is highly questionable: Jaegwon Kim and more recently Frank Jackson argue that the supervenience of the moral on the non-moral implies that for any moral predicate there is a co-extensive non-moral predicate. ${ }^{9}$ Jackson (1998: 124) emphasizes that moral vocabulary may still be practically indispensable. On his view, the non-moral story may be too long and disjunctive to be any use: indeed, the non-moral story may involve infinitely long disjunctions.

Perhaps Majors was thinking just of practically specifiable non-moral conditions. There is a crude but effective way of supplying these: introduce a succinct new predicate - ' $G$ ', say - and stipulate that it means the same as Jackson's long, disjunctive predicate. Then the conditions are these:

$x$ is morally good if and only if $x$ is G.

The arguments given above provide another way for moral realists to specify non-moral conditions for possessing moral properties. For instance:

$x$ is morally good if and only if $x$ has a realizer of moral goodness.

Although the right-hand side includes a moral predicate, the realist should agree that it picks out a non-moral way for something to be. That is because realists hold that the moral is grounded in the non-moral.

I do not know why Majors claims that explanations drawing implicitly on the generalization 'Injustice causes revolt' could be matched by non-moral explanations only if 'the property of being unjust could be picked out by a non-moral predicate'. Where the inference to the best explanation arguments are concerned, the important question is not whether there is a non-moral predicate picking out the property of moral goodness, nor even whether there is a non-moral predicate with

isolate those features that determine moral ones without employing moral concepts and, thus, are unable to construct configuring cause explanations entirely in terms of these determining features.

9 See Kim 1994, Kim 1990, Jackson 1998: 122-3, Jackson 2001: 653-6; and, for critical commentary, Streumer 2011. 
the same extension as 'morally good'. Rather, the question is whether explanations presupposing moral realism are superior to non-moral explanations. Majors thinks they are: 'any explanatory work done by adverting to the property [of goodness] can be done only at the level of moral theory'. This claim is undercut by the arguments I have offered. We are not faced with a choice between the explanatory groupings offered by moral concepts and the over-detailed categorizations made by non-moral ones. We can help ourselves to the illuminating categorizations which moral concepts provide, and exploit these in explanation, without having to sign up to moral realism. Although we use moral language in making the categorization - for instance, when we talk about an 'alleged realizer of injustice' - we do not use the language in such a way as to imply moral realism.

Talk of 'using moral language, but not in such a way as to imply moral realism' recalls wellknown forms of metaethical anti-realism: both moral fictionalists and moral expressivists may be described as recommending that we use moral language whilst denying that our use need commit us to moral realism. Here I have offered another anti-realist way to exploit moral language. In place of the concepts involved in fictionalist and expressivist metaethics, I have invoked 'alleged'-talk ('The fact that the society had an alleged realizer of injustice') and counterfactuals ('The fact that the society was such that, if moral realism were true, it would be unjust'). My aim has been to weaken the cases for both mathematical and moral realism by providing a new attack on inference to the best explanation arguments for realism. Whilst I do not claim that my attack definitely succeeds, I do claim that multiple realizability fails to defeat it. ${ }^{10}$

Works cited [One reference removed for review]

Brink, David O. 1989. Moral Realism and the Foundations of Ethics. Cambridge: Cambridge University Press.

Chihara, Charles 1990. Constructibility and Mathematical Existence. Oxford: Oxford University Press. Clark, Michael J. and David Liggins 2012. Recent work on grounding. Analysis 72: 812-23. Correia, Fabrice and Benjamin Schnieder 2012. Grounding: an opinionated introduction. In their (eds) Metaphysical Grounding: Understanding the Structure of Reality. Cambridge: Cambridge University Press: 1-36.

Colyvan, Mark 2001. The Indispensability of Mathematics. New York: Oxford University Press. Colyvan, Mark 2010. There is no easy road to nominalism. Mind 119: 285-306.

10 Thanks to ... 
Cuneo, Terence 2006. Moral facts as configuring causes. Pacific Philosophical Quarterly 87: 141-62. Daly, Chris 2012. Scepticism about grounding. In Fabrice Correia and Benjamin Schnieder (eds) Metaphysical Grounding: Understanding the Structure of Reality. Cambridge: Cambridge University Press: 81-100.

Dorr, Cian 2008. There are no abstract objects. In Theodore Sider, John Hawthorne, and Dean Zimmerman (eds) Contemporary Debates in Metaphysics. Malden, MA: Blackwell: 32-63.

Field, Hartry 1980. Science without Numbers: A Defence of Nominalism. Oxford: Blackwell.

Field, Hartry 1989. Realism, Mathematics and Modality. Oxford: Blackwell.

Fine, Kit 1995. Ontological dependence. Proceedings of the Aristotelian Society 95: 269-90.

Harman, Gilbert 1977. The Nature of Morality: An Introduction to Ethics. New York: Oxford University Press.

Jackson, Frank 1998. From Metaphysics to Ethics: A Defence of Conceptual Analysis. Oxford: Clarendon Press.

Jackson, Frank 2001. Responses. Philosophy and Phenomenological Research 62: 653-64.

Kim, Jaegwon 1984. Concepts of supervenience. Philosophy and Phenomenological Research 45: 153-76.

Kim, Jaegwon 1990. Supervenience as a philosophical concept. Metaphilosophy 21: 1-27.

Lyon, Adian 2012. Mathematical explanations of empirical facts, and mathematical realism. Australasian Journal of Philosophy 90: 559-78.

Majors, Brad 2003. Moral explanation and the special sciences. Philosophical Studies 113: 121-52.

Majors, Brad 2007. Moral explanation. Philosophy Compass 2/1: 1-15.

Nolan, Daniel 1997. Impossible worlds: a modest approach. Notre Dame Journal of Formal Logic 38: $535-72$.

Pincock, Christopher 2007. A role for mathematics in the physical sciences. Noûs 41: 253-75.

Plebani, Matteo MS. Nominalistic content, grounding, and covering generalizations.

Railton, Peter 1998. Moral Explanation and Moral Objectivity. Philosophy and Phenomenological Research 58: $175-182$.

Raven, Michael J. 2013. Is ground a strict partial order? American Philosophical Quarterly 50: 193-201.

Rodriguez-Pereyra, Gonzalo 2005: Why truthmakers. In Helen Beebee and Julian Dodd (eds)

Truthmakers: The Contemporary Debate. Oxford: Clarendon Press: 17-31.

Rosen, Gideon 2010. Metaphysical dependence: grounding and reduction. In Bob Hale and Aviv Hoffmann (eds) Modality: Metaphysics, Logic, and Epistemology. Oxford: Oxford University Press: 109-35. 
Sayre-McCord, Geoffrey 1988. Moral theory and explanatory impotence. Midwest Studies in Philosophy 12: 433-57.

Schaffer, Jonathan 2012. Grounding, transitivity, and contrastivity. In Fabrice Correia and Benjamin Schnieder (eds) Metaphysical Grounding: Understanding the Structure of Reality. Cambridge: Cambridge University Press: 122-38.

Schnieder, Benjamin 2009. 'By': a refutation of the Anscombe thesis. Linguistics and Philosophy 31: 649-69.

Sinclair, Neil 2011. The explanationist argument for moral realism. Canadian Journal of Philosophy 41:1-24.

Streumer, Bart 2011. Are normative properties descriptive properties? Philosophical Studies 154: 32548.

Sturgeon, Nicholas L. 1985. Moral explanations. In David Copp and David Zimmerman (eds) Morality, Reason and Truth. Totowa, N.J.: Rowan and Allanheld: 49-78.

Trogdon, Kelly 2013. An introduction to grounding. In Miguel Hoeltje, Benjamin Schnieder, and Alex Steinberg (eds) Varieties of Dependence: Ontological Dependence, Grounding, Supervenience, Response-Dependence. München: Philosophia Verlag: 97-122.

Williamson, Timothy 2007. The Philosophy of Philosophy. Oxford: Blackwell.

Yablo, Stephen 2012. Explanation, extrapolation, and existence. Mind 121: 1007-29.

Zangwill, Nick 2006. Moral epistemology and the Because Constraint. In James Drier (ed.) Contemporary Debates in Moral Theory. Malden MA: Blackwell: 263-81. 